Dunamis: Jurnal Teologi dan Pendidikan Kristiani

Volume 6, Nomor 1 (Oktober 2021)

ISSN 2541-3937 (print), 2541-3945 (online)

https://www.sttintheos.ac.id/e-journal/index.php/dunamis

DOI: 10.30648/dun.v6i1.489

Submitted: 21 Desember 2020

Accepted: 29 Maret 2021

Published: 20 Oktober 2021

\title{
Perbandingan Konsep Teodise John Calvin dan C. S. Lewis serta Relevansinya terhadap Sikap Fatalistik dalam Menghadapi Covid-19
}

\author{
Thio Christian Sulistio $^{1^{*}}$; Esther Gunawan ${ }^{2}$ \\ Sekolah Tinggi Teologi SAAT ${ }^{1}$; Gereja Kristen Kalam Kudus Malang ${ }^{2}$ \\ christian.sulistio@seabs.ac.id*
}

\begin{abstract}
The world is currently enduring an epidemic of COVID-19 which causes suffering and pain. Facing the COVID-19 pandemic, Indonesian people have shown various responses. One pupular respond is theological fatalism, which believe that God has determined everything so that human efforts and actions are not necessary. In connection to this, the question arouse whether Christian theology, especially Christian theodicy, which was represented in this paper by John Calvin and C. S. Lewis, fell into fatalism? To answer this question, the writer would compare of the two theodicies by using a literature research. Through this research, it was concluded that neither John Calvin's theodicy nor C. S Lewis's had fallen into theological fatalism. Both emphasized free will and human responsibility in making choices and actions. The right attitude is to submit to the authority of God's word which commands us to act by doing good to others who are suffering and sick.
\end{abstract}

Keywords: Covid-19; theodicy; John Calvin; C. S. Lewis; theological fatalism

\begin{abstract}
Abstrak
Dunia saat ini sedang dilanda wabah penyakit COVID-19 yang menyebabkan penderitaan dan kesakitan. Berhadapan dengan pandemi COVID-19, manusia Indonesia menunjukkan berbagai respon. Salah satu yang umum adalah fatalisme teologis yakni kepercayaan bahwa Allah sudah menetapkan segala sesuatu sehingga usaha dan perbuatan manusia tidak membuat perbedaan dan dampak di dalam sejarah kehidupan. Berkaitan dengan hal tersebut muncul pertanyaan apakah teologi Kristen, khususnya teodise Kristen, yang diwakili di dalam paper ini oleh John Calvin dan C. S. Lewis jatuh ke dalam fatalisme? Untuk menjawab pertanyaan tersebut penulis akan membandingkan kedua teodise tersebut dengan menggunakan studi pustaka. Melalui penelitian tersebut disimpulkan bahwa baik teodise John Calvin maupun C. S Lewis tidak jatuh ke dalam fatalisme teologis. Kedua-duanya sama-sama menekankan kehendak bebas dan tanggung jawab manusia di dalam melakukan pilihan dan tindakan. Sikap yang tepat adalah tunduk kepada otoritas firman Tuhan yang memerintahkan kita untuk bertindak dengan berbuat baik kepada sesama yang menderita dan sakit.
\end{abstract}

Kata Kunci: Covid-19; teodise; John Calvin; C. S. Lewis; fatalisme teologis 


\section{PENDAHULUAN}

Dunia kita pada saat ini sedang dilanda pandemi COVID-19 yakni sebuah penyakit yang disebabkan oleh virus korona. Penyakit ini cukup mematikan dan menyebabkan masalah kesehatan, ekonomi, sosial, budaya, dan kehidupan keagamaan di seluruh dunia. Di dalam menghadapi pandemi ini orang memiliki berbagai macam sikap yang berbeda dan salah satu sikap umum yang muncul adalah sikap fatalisme yang memiliki ekspresi seperti: "pasrah saja atas kehendak Tuhan untuk makhluknya, tanpa perlu ikhtiar tertentu." Hingga sampai pada pernyataan, "tak perlu takut corona, takutlah cukup pada Tuhan."1 Fatalisme seperti ini adalah fatalisme teologis yakni sebuah pandangan yang berpendapat bahwa semua peristiwa telah ditetapkan untuk terjadi dan apapun yang kita sebagai manusia lakukan tidak akan dapat mengubahnya. Faktor yang menjamin bahwa peristiwa-peristiwa tersebut pasti terjadi terletak pada ketetapan kehendak Allah atau pra-pengetahuan Allah sebelum peristiwa tersebut terjadi. ${ }^{2}$ Sedangkan segala sikap dan tindakan manusia ti-

\footnotetext{
1 Akmal Salim Ruhana and Haris Burhani, Pengetahuan, Sikap Dan Tindakan Umat Beragama Menghadapi Covid-19, 2020: 9-10, https:// simlitbangdiklat.kemenag.go.id/simlitbang/spdata/u pload/dokumen-penelitian/1592454380Laporan_ UmatVSCovid_.pdf.

2 Carl Hoefer, "Causal Determinism," Stanford Encyclopedia of Philosophy, 2016, https://plato. stanford.edu/entries/determinism-causal/\#Int.; Matthew Duvalier McCauley, "The Problem of
}

dak akan menghasilkan perubahan pada nasib akhir manusia. Fatalisme ini adalah fatalisme yang dianut oleh orang teisme yakni orang yang menganut pandangan adanya Allah yang bersifat pribadi. Sehingga fatalisme teologis ini dapat (namun tidak harus) dianut oleh orang beragama seperti Kristen, Muslim, maupun Yudaisme. Fatalisme teologis ini telah menjadi sebuah pandangan hidup yang tidak terpisahkan dalam hidup beragama dan bermasyarakat di Indonesia khususnya pada waktu manusia berhadapan dengan eksistensi penderitaan dan bencana di dalam kehidupan mereka. Saifudin Zuhri sebagaimana dikutip oleh Ahmad Sabir menjelaskan:

Di negara kita, pandangan teologis fatalistik mungkin masih kuat menancap dalam kesadaran keberagamaan banyak orang. Sehingga itu berdampak pada rendahnya kadar responsibility terhadap eksistensi alam. Terjadinya bencana alam tidak dibaca sebagai akibat dari pola relasi yang salah kaprah yang kita bangun dengan alam semesta. Tapi dilimpahkan dan dialihkan sebagai adzab, peringatan, kemurkaan dan pelajaran yang Tuhan turunkan kepada manusia Indonesia. Kita memang suka melempar tanggung jawab kepada 'langit.' 3

Theological Fatalism," Logos 11, 2014: 56. Fatalisme teologis berbeda dengan fatalisme orang-orang yang menganut pandangan panteisme, di mana nasib atau takdir yang tidak berpribadi yang mengatur nasib manusia dan memastikan semua peristiwa terjadi, yang disebut juga dengan fatalisme metafisik atau fatalisme panteistik.

3 Ahmad Sabir, "Gambaran Umum Persepsi Masyarakat Terhadap Bencana Di Indonesia," Jurnal Ilmu Ekonomi dan Sosial 5, no. 3 (2016): 304-326. 
Pandangan fatalisme teologis ini mengakibatkan manusia tidak mau mengambil tanggung jawab di dalam menghadapi bencana dan penderitaan serta melemparkan semuanya kepada kehendak Allah dan hanya bersikap pasrah semata. Bencana semata dipandang sebagai hukuman Allah dan upaya manusia adalah hanya berdoa memohon ampun kepada Allah dan menerima bencana dan penderitaan dengan sabar dan tawakal kepada Allah. Tentu saja sikap fatalistik seperti ini di dalam menghadapi bencana dan penderitaan khususnya COVID-19 bukan sikap yang tepat karena mengabaikan kebenaran teologis yang lain yakni pentingnya respons manusia yang tepat terhadap situasinya.

Di tengah-tengah sikap fatalisme manusia Indonesia ini muncul pertanyaan apakah teologi Prostestan yang injili di Indonesia mengajarkan fatalisme teologis?

\footnotetext{
${ }^{4}$ Penulis memilih pandangan John Calvin karena pandangan dia banyak dianut oleh orang-orang Kristen di Indonesia serta C. S. Lewis karena kepopuleran dia di Indonesia belakangan ini. Buku, novel, dan film dari novel-novel Lewis sudah banyak diterjemahkan dan beredar di Indonesia.

5 Teodise adalah istilah yang pertama kali diperkenalkan oleh Gottfried Leibniz seorang filsuf Jerman, berasal dari dua kata Yunani Theos (Allah) dan dike (keadilan) sehingga pengertian teodise adalah suatu bentuk pembelaan untuk membenarkan (justify) maksud dan tindakan Allah yang Mahabaik dan Mahaadil yang mengizinkan keberadaan kejahatan (evil) ke dalam dunia ini dan Ia tidak dapat dipersalahkan atas keberadaan kejahatan tersebut. Lihat Chad V. Meister, Evil: A Guide for the Perplexed, 2nd ed. (New York: Bloomsbury, 2018), 42.; Jessica Novia Layantara, "Kritik Terhadap Teologi Proses Dan Pembelaan Terhadap Pandangan 'Greater
}

Untuk menjawab pertanyaan tersebut penulis memilih pandangan teologi dari John Calvin (1509-1564) ) dan C. S. Lewis (1898-1963) sebagai perwakilan. ${ }^{4}$ Penulis akan membandingkan dua konsep teodise ${ }^{5}$ mereka di mana konsep teodise John Calvin mengusung kehendak bebas kompatibilisme dan konsep teodise C. S. Lewis mengusung kehendak bebas libertarian. ${ }^{6}$ Perbandingan ini bertujuan menjawab pertanyaan apakah teodise John Calvin dan C. S. Lewis jatuh kepada pandangan fatalisme teologis? Jika tidak, unsur-unsur pemahaman seperti apa yang menjadikan paham teodise mereka tidak fatalistik. Setelah itu penulis akan membuat relevansi dari pandangan-pandangan tersebut kepada konsep fatalisme teologis yang dianut oleh kalangan Kristen di Indonesia.

Good' Dalam Menanggapi Masalah Kejahatan," Veritas: Jurnal Teologi dan Pelayanan 16, no. 2 (December 1, 2017): 155-168, accessed September 10, 2021, https://ojs.seabs.ac.id/ index.php/Veritas/ article/view/16.

${ }^{6}$ Kompatibilisme atau determinisme lunak adalah sebuah pandangan yang berpendapat bahwa determinisme kompatibel dengan kehendak bebas manusia dan mendefinisikan kehendak bebas manusia sebagai kemampuan manusia untuk bertindak tanpa dikekang atau dipaksa dari luar. Sedangkan kehendak bebas libertarian adalah pandangan yang dianut oleh inkompatibilisme yang berpendapat bahwa manusia mampu melakukan yang sebaliknya dari apa yang ia lakukan saat ini. Luke Van Horn, "On Incorporating Middle Knowledge into Calvinism: A Theological/ Metaphysical Muddle?," JETS 55, no. 4 (2012): 807-834. 


\section{METODE PENELITIAN}

Penulis akan menggunakan metode studi pustaka terhadap sumber-sumber primer maupun sumber sumber sekunder yang berkaitan dengan teodise Calvin dan Lewis. Melalui studi pustaka, penulis pertama-tama akan menganalisis literatur yang terkait untuk mendeskripsikan pandangan teodise dari Calvin maupun Lewis. Lalu setelah itu penulis melakukan komparasi antara kedua teodise tersebut dan menarik kesimpulan konsep-konsep apa yang membuat pandangan mereka fatalisme teologis atau bukan fatalisme teologis. Pada akhirnya, penulis akan membuat implikasi dari pandanganpandangan mereka yang menjadikan mereka fatalisme atau bukan fatalisme sebagai sumbangsih terhadap fatalisme teologis yang marak di Indonesia sebagai hasil dari studi komparasi ini.

\section{HASIL DAN PEMBAHASAN}

\section{Konsep Teodise Calvin}

Bagi Calvin, manusia harus memiliki dua jenis pengetahuan yang tidak bisa dipisahkan dan saling terkait satu dengan

\footnotetext{
7 Jordan Steffaniak, "Bound by the Word of God: John Calvin's Religious Epistemology," Puritan Reformed Journal 10, no. 2 (2018): 121-122.

${ }^{8}$ Pada dasarnya, konsep-konsep teologis Calvin adalah menghidupkan kembali Agustinianisme, sebagaimana pula konsep-konsep teologis Luther. Agustinus banyak mempengaruhi Calvin dalam doktrin-doktrinnya termasuk konsep teodisenya. Jessica Novia Layantara, "Determinisme, Masalah Kejahatan dan Penyebab Sekunder Menurut John Calvin," Jurnal Amanat Agung 11, no. 2 (December
}

yang lain, yakni: pengetahuan tentang Allah dan pengetahuan tentang diri sendiri. ${ }^{7}$ Premis teologis inilah yang mendasari setiap doktrin Calvin, termasuk pula konsepnya tentang teodise. ${ }^{8}$

\section{Konsep Calvin Tentang Kejahatan Sebagai Kurangnya Kebenaran dan Melawan Allah}

Bagi Calvin, kejahatan harus dipahami secara universal, objektif dan dalam kerangka providensia Allah. Walaupun bukan secara langsung disebabkan oleh Allah namun kejahatan tetap berada dalam kedaulatan-Nya, sebab Dia adalah penyebab ultima atas segala sesuatu. ${ }^{9}$ Menurut Calvin, kejahatan bukan sekadar korupsi atau kurangnya kebaikan. Kejahatan berawal dari kejatuhan manusia dalam dosa dan bukan merupakan tanggung jawab Allah. Bagi Calvin, kejahatan dapat digambarkan secara negatif sebagai kurangnya kebenaran (righteousness) dan secara positif sebagai sebuah perlawanan atau permusuhan terhadap Allah. ${ }^{10}$ Kejahatan natural, seperti wabah penyakit dan gempa bumi, adalah konse-

1, 2015): 297-332, accessed September 10, 2021, https://ojs.sttaa.ac.id/index.php/JAA/article/view/18 1.

${ }^{9}$ Nico Vorster, "The Augustinian Type of Theodicy: Is It Outdated?," Journal of Reformed Theology 5, no. 1 (January 1, 2011): 26-48, accessed September 10, 2021, https://brill.com/view/journals/jrt/5/1/ article-p26_4.xml.

${ }^{10}$ Timothy E. Miller, "Reformed Theodicy: Calvin's View of the Problem of Evil," Puritan Reformed Journal 10, no. 1 (2018): 121. 
kuensi kejatuhan manusia ke dalam dosa dan akibat yang timbul karena penghukuman Allah atas dosa pertama manusia.

\section{Pembelaan Terhadap Allah}

Calvin membangun konsep teodisenya di atas fondasi bahwa Allah adalah Allah yang berdaulat, penguasa dunia dan sejarah manusia, termasuk kejahatan. Pengakuan terhadap kedaulatan Allah tersebut pada akhirnya menuntut manusia mengakui bahwa Allah tetap benar dan baik di balik segala masalah kejahatan yang menimpa manusia dan makhluk ciptaan-Nya. Pembelaan Calvin terhadap kebenaran Allah adalah: pertama, Allah adalah Allah yang berdaulat, penguasa dunia dan sejarah manusia. Bagi Calvin, dari semua karya Allah yang paling jelas menunjukkan kedaulatan Allah adalah doktrin providensia Allah. Ia meyakini bahwa Allah sebagai Allah yang Mahakuasa dan berdaulat adalah penyebab segala sesuatu dan yang memerintah atas seluruh ciptaan. Calvin menegaskan bahwa Allah yang Mahakuasa tersebut mengatur segala sesuatu sedemikian rupa sehingga tidak ada suatu apa pun terjadi di luar dari

\footnotetext{
11 John Calvin, Institutes of the Christian Religion, ed. John T. McNeill (Philadelphia: Westminster, 1960), I.xvi.2.

12 Ibid, I.xvi.2, 8; I.xvi.3.

13 Alan R. Rhoda, "Gratuitous Evil and Divine Providence," Religious Studies 46, no. 3 (September 2010): 281-302, accessed September 10, 2021, https://www.cambridge.org/core/journals/religiousstudies/article/abs/gratuitous-evil-and-divineprovidence/5C4B9995EA2D65338703174DCA6F6 $1 \mathrm{AE}$.
}

kehendak-Nya. $^{11}$ Karakter providensia Allah tersebut bersifat partikular, meliputi peristiwa-peristiwa yang terjadi secara spesifik, bersifat terus-menerus dan aktif. ${ }^{12}$ Konsep Calvin ini mengafirmasi bahwa Allah menetapkan segala sesuatu secara detail untuk mewujudkan suatu dunia dengan rangkaian sejarah yang Ia inginkan. ${ }^{13}$ Providensia Allah juga tidak dapat dipisahkan dari keberadaan-Nya sebagai Sang Pencipta. Allah adalah Pencipta yang menopang seluruh tatanan dan eksistensi dari ciptaan. ${ }^{14}$ Kehendak Allah tersebut dieksekusi dalam setiap apa yang terjadi dalam diri manusia sehingga kegagalan untuk memahami partikularitas providensia-Nya berarti kegagalan untuk memahami karya Allah sebagai Pencipta dan Pemelihara. ${ }^{15}$ Karena dunia ini diciptakan secara khusus demi manusia maka manusia harus memahami tujuan Allah atas penciptaan dunia tersebut. ${ }^{16}$ Bahkan apa yang dianggap sebagai nasib sebenarnya adalah juga bagian dari rencana dan kehendak Allah dan tidak ada yang terjadi di luar kehendak-Nya. ${ }^{17}$ Implikasi dari providensia Allah kepada manusia

\footnotetext{
${ }^{14}$ Calvin, Institutes of the Christian Religion, I.xvi.1; bandingkan dengan I.xvii.11.

${ }^{15}$ Calvin menghubungkan pengetahuan akan providensia dengan iman dan akal budi di mana melalui akal budinya manusia mengakui akan kekuatan di balik penciptaan, yakni Allah sendiri, Sang Penguasa yang aktif menopang, memelihara dan juga peduli terhadap segala sesuatu dalam ciptaan-Nya (Calvin, Institutes of the Christian Religion, I.xvi.1). ${ }^{16}$ Calvin, Institutes of the Christian Religion, I.xvi.6. ${ }^{17}$ Ibid, I.xvi.9.
} 
atas masalah kejahatan adalah kebersandaran manusia kepada kedaulatan-Nya tersebut, ${ }^{18}$ sehingga sikap yang tepat dari manusia adalah tunduk total kepada otoritas atau kehendak-Nya.

Kedua, Allah adalah Allah yang berdaulat atas kejahatan. Karena Allah adalah Penguasa atas dunia dan sejarah manusia, maka sebagai konsekuensi logis, kejahatan berada pula di bawah kontrol dan kedaulatan-Nya, bahkan setan pun tidak luput dari batasan-batasan kedaulatan-Nya. ${ }^{19}$ Calvin menerjemahkan kedaulatan Allah atas kejahatan dengan memahami bahwa Dia telah menetapkan kejahatan dengan ketetapan-Nya yang mengerikan. ${ }^{20}$ Calvin mengatributkan kejahatan sebagai hal yang dikehendaki oleh-Nya, bahkan ia menolak jika Dia dikatakan sekadar mengizinkan kejahatan. ${ }^{21}$ Kejatuhan dan dosa asal sebagai sumber dari kejahatan manusia, telah ditetapkan dari awal berdasarkan prapengetahuan dan prapenetapan-Nya. ${ }^{22}$ Namun demikian, Calvin menolak jika Allah disebut

\footnotetext{
18 Ibid.

${ }^{19}$ Ibid, I.xviii.2. Hal ini ditekankan juga oleh Calvin dalam penjelasan khotbahnya pada bagian Ayub 1:12 dimana ia menafsirkan bahwa setan pun hanya berfungsi sebagai instrumen di tangan Allah.

${ }^{20}$ Ibid, I.xv.8, lihat juga III.xxiii.7.

21 Concerning the Eternal Predestination of God (London: James Clarke, 1997), 176. Lihat juga Calvin, Institutes of the Christian Religion, I.xviii.3. Paul Helm menjelaskan bahwa Calvin di sini memakai istilah ketetapan Allah yang mengizinkan kejahatan (willing permission), Paul Helm, John Calvin's Ideas (Oxford: Oxford University Press, 2006), 99, 125.
}

sebagai penyebab dari kejahatan. Calvin membuat perbedaan antara Allah sebagai penyebab pertama dan manusia sebagai penyebab kedua. ${ }^{23}$ Allah sebagai penyebab pertama adalah penyebab tidak langsung dan manusia sebagai penyebab kedua adalah penyebab langsung kejahatan. Di titik ini ada perbedaan antara kausalitas Allah dan manusia. ${ }^{24}$ Allah bukan pelaku kejahatan tetapi manusialah yang melakukan kejahatan. Lebih jauh, Calvin juga mengatakan bahwa Allah dengan prapengetahuan-Nya telah menetapkan apa yang akan terjadi atas diri manusia, termasuk kejahatan, namun Ia bekerja dengan tidak melanggar kehendak bebas manusia dengan memaksa manusia melakukan sesuatu yang tidak mau manusia itu lakukan. Allah bekerja menjalankan ketetapan-Nya sesuai dan melalui natur manusia itu sendiri yang bebas.

Ketiga, Allah adalah Allah yang benar dan baik. Calvin memandang kemahakuasaan Allah jauh dari bersifat tirani sebab kemahakuasaan-Nya tersebut tidak

\footnotetext{
22 Calvin, Institutes of the Christian Religion, III.xxiii.7; lihat juga III.xxiii.8.

${ }^{23}$ Paul Helm, The Providence of God (Grand Rapids: InterVarsity Press, 1994), 178-179., melihat bahwa Calvin menafsirkan hal ini dengan pendekatan model kausal, di mana Calvin membedakan antara intensi dan tujuan manusia dengan intensi dan tujuan termulia Allah di dalam menetapkan tindakan yang dikerjakan oleh penyebab kedua. Lihat juga Calvin, Institutes of the Christian Religion, I.xviii.4.

24 Calvin, Institutes of the Christian Religion, I.viii.1.
} 
dapat dipisahkan dari keadilan, kebijaksanaan, dan kebaikan-Nya, sehingga jelas bahwa bagi Calvin, Allah adalah Allah yang benar dan baik dalam segala keputusan-keputusan yang Ia ambil. Karena kemahakuasaan Allah tidak bisa dipisahkan dari keadilan, kebijaksanaan dan kebaikan-Nya maka sebagai konsekuensi, gagasan keadilan dan kebaikan-Nya tersebut bergantung secara eksklusif hanya pada Allah. Allah dengan kehendak-Nya yang ilahi tidak terikat oleh hukum eksternal apa pun. Ia yang menetapkan kriteria keadilan dan kebaikan bagi manusia. Mengenai hal ini, Calvin tidak bermaksud membuktikan bahwa Allah mempunyai kehendak ganda, sebab baginya, kehendak-Nya lebih bersifat tunggal. ${ }^{25}$ Dalam hubungannya dengan rencana Allah atas manusia, kehadiran kejahatan adalah tetap baik (walaupun kejahatan pada dirinya sendiri tetap merupakan hal yang buruk), sebab tidak ada penetapan Allah yang salah. ${ }^{26}$ Pemahaman ini pada akhirnya menjadi titik tolak untuk memahami mengapa Calvin melihat bahwa penderitaan dapat diterima dan Allah bukan menjadi pihak yang bersalah. Yang menjadi pertanyaan kemu-

\footnotetext{
${ }^{25}$ Ibid, I.xviii.3.

${ }^{26}$ Ibid, III.xxiii.7. Lihat juga pembelaan Calvin terhadap Allah yang benar dalam khotbah Ayub "God's Power Is Just" dalam John Calvin, Sermons from $J o b$, trans. Leroy Nixon (Port St. Lucie: Solid Ground Christian Books, 2011), 258-271.

${ }^{27}$ C. J. Kinlaw, "Determinism and the Hiddenness of God in Calvin's Theology," Religious Studies 24, no. 4 (1988): 497-509, accessed September 13,
}

dian adalah, bagaimana Calvin menjawab penderitaan yang dialami orang-orang yang tidak bersalah atau orang percaya? Mengapa Alkitab tidak dengan jelas mengungkapkan hal tersebut?

\section{Kehendak Allah yang Tersembunyi (Deus}

\section{Absconditus)}

Penekanan kepada kedaulatan Allah serta kehendak bebas manusia yang dibatasi oleh kedaulatan-Nya tersebut membawa Calvin kepada konsep kehendak Allah yang tersembunyi. Calvin menjelaskan adanya kehendak Allah yang tersembunyi yang berada di luar dari penyataan diri Allah dalam diri Yesus Kristus. ${ }^{27}$ Masih ada misteri Allah di luar penyataan Allah melalui diri Yesus Kristus. Ia meyakini bahwa penyataan diri Allah dalam Yesus Kristus tidak membuang misteri Allah. Jika Alkitab tidak menyatakan eksistensi Allah yang utuh dan hanya terbatas pada penyataan dalam diri Yesus Kristus, hal itu berkaitan dengan masalah keselamatan. ${ }^{28}$ C. J. Kinlaw mengatakan bahwa bagi Calvin, penyataan diri Allah dalam diri Yesus belum menyatakan keberadaan dan natur diri Allah yang utuh

2021, https://www.cambridge.org/core/journals/ religious-studies/article/abs/determinism-and-thehiddenness-of-god-in-calvins-theology/55183C355 FAB9E17D78DB43AE69D4C18. Ide ini menjadi pusat perhatian penting dalam memahami teologi Calvin, terutama dalam memahami konsep teodisenya.

${ }^{28}$ Calvin, Institutes of the Christian Religion, I.x.2. 
secara ontologis. ${ }^{29}$ Sehingga di balik penyataan-Nya dalam diri Yesus maupun Alkitab tetap terdapat hikmat dan keadilan-Nya yang dalam dan tidak akan mampu manusia pahami sepenuhnya. Hikmat dan keadilan Allah yang dalam tersebut tersirat dalam pengajaran kitab Ayub dan manusia dengan kapasitasnya tetap tidak akan memahami hikmat dan keadilan Allah. ${ }^{30}$

Bagi Calvin, manusia tidak mungkin memiliki pengetahuan yang lengkap tentang Allah dan ketetapan-Nya hanya berdasarkan pada firman-Nya. Selalu ada misteri berkaitan dengan hakikat dan rencana Allah terhadap ciptaan-Nya. Hal ini karena adanya perbedaan antara Allah yang tak terbatas dan manusia yang terbatas. Ketika yang terbatas memaksakan keinginannya untuk memahami yang tidak terbatas secara tuntas, yang akan terjadi adalah hilangnya perbedaan ontologis Pencipta dengan ciptaan. Allah menetapkan bahwa manusia memiliki keterbatasan untuk mengenali eksistensi dan kehendak-Nya secara ontologis. ${ }^{31}$ Walaupun Calvin menekankan bahwa manusia memiliki keterbatasan terhadap pengenalan tentang Allah secara ontologis, bukan berarti ia menolak bahwa manusia dapat mengenali-Nya. Manusia tetap mam-

\footnotetext{
${ }^{29}$ Kinlaw, "Determinism and the Hiddenness of God in Calvin's Theology."

${ }^{30}$ John Calvin, Calvin's Calvinism: A Treatise on the Eternal Predestination of God, trans. Henry Cole (Grand Rapids: Reformed Free, 1994), 327.
}

pu mengenali Allah, baik melalui wahyu umum dan secara khusus melalui wahyu khusus, namun semua ini tidak akan membawa manusia kepada pengenalan yang sempurna tentang Allah. Wahyu khusus hanya akan membawa manusia kepada keselamatan dan bukan kepada pengenalan yang utuh tentang Dia sehingga tidak ada seorang pun yang mampu melampaui jurang yang membentang antara Allah dan manusia.

Selain alasan keterbatasan ontologis manusia, alasan lain di balik ketersembunyian kehendak Allah tersebut adalah kehendak-Nya sendiri yang menetapkan batas bagi penyataan diri-Nya. Manusia hanya dapat mengenali Allah sejauh apa yang Dia nyatakan dalam Alkitab, yakni karya keselamatan yang dapat manusia pahami walaupun secara parsial dan terpisah-pisah. Calvin berusaha untuk menghindari segala bentuk intelektualisme skolastik sebab manusia tidak mungkin dapat memahami Allah seutuhnya, apalagi menunjukkan eksistensi-Nya. Meskipun Calvin nampak mengekspresikan konsep-konsep teologinya secara rasional, namun ia tidak pernah mengisyaratkan bahwa logika manusia yang mandiri dan lepas dari wahyu Allah, mampu mencapai pengetahuan-Nya yang

\footnotetext{
31 Calvin, Institutes of the Christian Religion, I.xviii.3, I.xvii.1-2.
} 
sempurna. Manusia sebenarnya berada dalam posisi tidak mungkin memahami hikmat Allah ataupun menyelidiki rahasiaNya. Bagi Calvin, firman Allah bukanlah untuk memuaskan segala pertanyaan manusia namun untuk memberitahukan kepada manusia tentang apa yang mereka perlu ketahui tentang keselamatan. Pengetahuan ini pula yang akan menjawab segala masalah eksistensial yang menyakitkan yang berasal dari penderitaan. Mereka yang mencari maksud Allah atas keselamatan manusia ini adalah mereka yang dikatakan mengenal Dia. Calvin lebih mengutamakan pengenalan tentang Allah berdasarkan apa yang telah Dia nyatakan, dibandingkan dengan apa yang tidak Dia nyatakan. Ia juga sangat menekankan implikasi yang terjadi berdasarkan relasi antara Allah dan manusia. Charles Partee menjelaskan demikian:

That is, Calvin is not interested in speculations about God in Himself, but in God, as revealed in His word. Calvin is concerned with God-forus. Thus to know God is to know His relationship to us, as it is revealed and to refuse to search for a hidden God. Of course, God-revealed-inus implies God-sovereign in Himself, but Calvin rejects the attempts to go behind or above God's revelation. ${ }^{32}$

Calvin juga menolak pengetahuan teoritis tentang Allah yang tidak berimpli-

\footnotetext{
${ }^{32}$ Charles Partee, Calvin and Classical Philosophy
} (Westminster: John Knox, 1977), 29. kasi terhadap mereka yang mengetahuinya seperti ia tegaskan melalui suatu pertanyaan: "What avails it, in short, to know a God with whom we have nothing to do?"33 Baginya, pengetahuan tentang Allah harus mengimplikasikan rasa takut dan hormat kepada-Nya, dan ketika mendapatkan segala kebaikan dari-Nya maka manusia harus memberikan kemuliaan hanya bagi Dia. Calvin sangat menyadari bahwa hanya di relung yang paling tersembunyi dari Allah, manusia akan mungkin menemukan jawaban atas banyak pertanyaan tentang eksistensi-Nya, termasuk masalah kejahatan. Perhatian utama Calvin dalam konsep kehendak Allah yang tersembunyi sebenarnya ada pada tujuan dari pekerjaan setia-Nya yang tersembunyi tersebut. Ia menyatakan bahwa ketersembunyian pekerjaan-Nya tersebut akan memberikan jawaban final dan definitif bagi masalah teodise.

Berdasarkan penjelasan di atas, dapat disimpulkan bahwa Calvin menempatkan konsep Allah dan kehendak-Nya yang tersembunyi sebagai hal yang sentral dalam konsep teodisenya. Baginya, Allah tetap menyembunyikan sebagian dari eksistensi dan kehendak-Nya atas manusia agar manusia bergantung sepenuhnya kepada kedaulatan-Nya yang mutlak, yang akan membawa kebaikan terbesar bagi manusia. Dalam

\footnotetext{
${ }^{33}$ Calvin, Institutes of the Christian Religion, I.ii.2.
} 
menghadapi pembatasan wahyu Allah dan ketersembunyian-Nya yang bersifat aktif ini, menurut Calvin, sikap yang paling tepat adalah tunduk kepada otoritas firman$\mathrm{Nya}^{34}$ Manusia perlu hidup berdasarkan otoritas firman-Nya bukan berdasarkan apa yang tersembunyi bagi manusia.

\section{Teodise Kebaikan yang Lebih Besar}

Calvin berusaha membangun konsep teodisenya secara biblikal, berpusat kepada Allah dan berdasarkan pada perspektif spiritual. Ia melihat penderitaan sebagai komponen integral dari kehendak Allah atas manusia. Allah mengizinkan bahkan menetapkan penderitaan dimana kejahatan dipakai-Nya sebagai agen untuk menggenapi kehendak-Nya. Namun demikian, suatu tindakan tidak memiliki kualitas moral dalam dirinya sendiri dan benar atau tidaknya suatu tindakan bergantung sepenuhnya pada motivasi sang pelaku. Segala tindakan-Nya selalu dimotivasi oleh hal-hal yang bersifat tulus dan suci, sedangkan manusia dimotivasi oleh kehendak-kehendak yang salah. Berdasarkan asumsi ini Calvin melihat bahwa, jika manusia menderita karena kejahatannya, maka jelas penderitaan tersebut

\footnotetext{
${ }^{34}$ Ibid, I.xviii.4.

${ }^{35}$ Matthew Ebenezer, "Calvin and Human Response to Suffering in the Psalm" (n.d.). Lihat juga kesimpulan Ebenezer tentang makna penderitaan bagi Calvin berdasarkan kitab Mazmur.
}

adalah akibat yang harus ditanggung oleh manusia itu sendiri.

Bagi Calvin, setiap penderitaan memiliki makna teologis dan tidak berada di luar koridor kedaulatan Allah. ${ }^{35}$ Ia melihat penderitaan sebenarnya hanya bersifat sementara demi kebaikan yang bersifat kekal berdasarkan kebaikan Allah, bukan sebagai tambahan yang tidak diundang dalam kehidupan orang Kristen. Sebaliknya, ia melihat penderitaan sebagai suatu keharusan: "It is, therefore, necessary that they [orang Kristen] should be exercised with various trials, and especially for this end, thay they may acknowledge that they have been wonderfully preserved by God amidst numberless death." 36 Konsep Calvin yang memandang setiap penderitaan memiliki makna teologis dan tidak berada di luar kedaulatan Allah mengerucut kepada satu kesimpulan jelas bahwa konsep teodisenya adalah teodise kebaikan yang lebih besar. Pada waktu ia melihat kejahatan hanya sebagai instrumen Allah untuk mendatangkan kebaikan bagi manusia, jelas menunjukkan bahwa ia menolak kejahatan yang berdiri sendiri, yang lepas dari kontrol Allah. ${ }^{37}$

\footnotetext{
${ }^{36}$ John Calvin, Commentary on the Book of Psalms Vol. I, trans. James Anderson (Edinburgh: Calvin Translation Society, 1945), 572.

37 John Calvin, Sermons on the Beatitudes (Edinburgh: Banner of Truth, 2006), 20.
} 


\section{Konsep Teodise C. S. Lewis ${ }^{38}$}

Lewis sangat menekankan pentingnya hukum-hukum alam. George Sayer mengatakan: "It is generally seen as his [Lewis's] most important phamplet and the best existing defense of objective value and natural law." ${ }^{39}$ Bahkan, ia mengatakan bahwa mereka yang berada di luar dari hukum alam tidak memiliki dasar untuk mengritik baik hukum alam atau apa pun. ${ }^{40}$ Hukum alam adalah fondasi bagi pemahaman tentang diri sendiri dan juga dunia di mana manusia tinggal. ${ }^{41}$

\section{Konsep Kejahatan C. S. Lewis: Kejahatan adalah Korupsi dari Kebaikan}

Sebagaimana pemahaman doktrin ortodoks, Lewis melihat natur kejahatan sebagai suatu privasi, korupsi dari kebaikan, suatu parasit dalam kebaikan. ${ }^{42}$ Konsep kejahatan tersebut senada dengan konsep kejahatan Agustinus dan Thomas Aquinas, ${ }^{43}$ dimana di dalam naturnya, kejahatan bertentangan dengan esensi dari kebaikan dan tidak memiliki eksistensi pada

\footnotetext{
${ }^{38}$ Pemaparan yang lebih lengkap tentang teodise C. S. Lewis oleh penulis dapat dilihat di Esther Gunawan, "Meneropong Makna Penderitaan Manusia Menurut Konsep Teodise C.S. Lewis," Veritas: Jurnal Teologi dan Pelayanan 16, no. 1 (June 1, 2017): 17-32, accessed September 13, 2021, https://ojs.seabs.ac.id/index.php/Veritas/article/vie w/8.

${ }^{39}$ George Sayer, Jack: C. S. Lewis and His Times (New York: Harper \& Row, 1988), 183.

${ }^{40}$ C. S. Lewis, "The Abolition of Man," in The Complete C. S. Lewis Signature Classics, ed. Joseph Rutt (San Francisco: Harper, 2002), 481.
}

dirinya sendiri. Kejahatan adalah sebuah penyimpangan atau kerusakan dari sesuatu yang baik. Hal ini tidak berarti kejahatan itu hanya sekadar ilusi manusia belaka namun sebagai kebaikan yang terdistorsi sehingga berbuahkan penderitaan. Clyde S. Kilby, menjelaskan konsep kejahatan Lewis demikian: "Like most theologians, he [Lewis] regards evil not as a thing-itself but rather the absence of good. There can be no such thing as "perfect badness" because when you take away from badness such good elements as intelligence, will, memory, energy, and even existence there will be nothing else."44

\section{Pembelaan Terhadap Allah}

Lewis percaya bahwa penjelasan filosofis terhadap penderitaan dapat dilakukan. Guna menjawab argumen-argumen ateisme, ia membahas tentang kemahakuasaan dan kebaikan Allah yang konsisten dengan fenomena penderitaan. ${ }^{45}$ Pembelaan terhadap Allah tersebut dapat dikatakan sebagai fondasi bagi konsep teodisenya yang

\footnotetext{
41 Grace P. Christian, ed., Mere Christianity (Bandung: Pioner Jaya, 2006), 31, 45-46.

${ }^{42}$ Robert Velarde, Conversations with C. S. Lewis: Imaginative Discussions about Life, Christianity and God (Downers Grove: InterVarsity, 2008), 54-55.

${ }^{43}$ Ronnie P. Campbell, Worldviews and the Problem of Evil (Bellingham: Lexham Press, 2019), 5.

${ }^{44}$ Clyde S. Kilby, The Christian World of C. S. Lewis (Grand Rapids: Eerdmans, 1964), 43.

${ }^{45}$ Jeff McInnis, Shadows and Chivalry: C. S. Lewis and George MacDonald on Suffering, Evil and Goodness (Milton Keynes: Paternoster, 2007), 54.
} 
menekankan kehendak bebas manusia. Lewis membuat pembelaannya sebagai berikut: pertama, Allah adalah Allah yang Mahakuasa. Lewis mengakui bahwa Allah adalah Allah yang Mahakuasa dan sempurna. Akan tetapi, baginya, kemahakuasaan Allah bukan berarti Allah sanggup melakukan segala sesuatu. Kemahakuasaan Allah dibatasi oleh hal-hal yang secara intrinsik bersifat mustahil untuk Allah lakukan: "not even Omnipotence can do what is selfcontradictory,"46 dan bahwa: "power to do all that is intrinsically possible, not to do the intrinsically impossible. You may attribute miracles to Him, but not nonsense. This is no limit to His power." ${ }^{47}$ Dengan kata lain, Allah berkuasa melakukan apa pun atas makhluk ciptaan sejauh itu tidak bertentangan dengan natur-Nya itu sendiri. Natur Allah melekat pada karakter-Nya dan Ia tidak dapat mencabut ketetapan atau hukum yang telah dibuat atau berkontradiksi dengan diri-Nya sendiri. Kemahakuasaan Allah berarti kuasa untuk melakukan segala sesuatu yang mungkin secara intrinsik, bukan untuk melakukan yang tidak mungkin secara intrinsik. ${ }^{48}$

Kedua, Allah adalah Allah yang Mahabaik. Konsep Lewis tentang kebaikan

\footnotetext{
${ }^{46}$ C. S. Lewis, "Miracles," in The Complete C. S. Lewis Signature Classics, ed. Joseph Rutt (San Francisco: Harper, 2002), 241.

${ }^{47}$ C. S. Lewis, The Problem of Pain (New York: Macmillan, 1968), 28.
}

Allah berangkat dari tiga hal yakni: (a) penolakannya atas ide Calvinisme tentang kerusakan total manusia, sehingga manusia tidak lagi mampu memahami kebaikan Allah; (b) kesadaran asali tentang dosa; dan (c) ketidakmengertian manusia tentang makna kebaikan Allah. ${ }^{49}$ Berdasarkan pada penolakan atas kerusakan total manusia serta topik kesadaran asali tentang dosa, ia mencoba untuk berhadapan dengan premis pertama yakni: jika Allah itu baik, Ia semestinya membuat semua makhluk ciptaan menikmati kebahagiaan yang sempurna. Tetapi karena kehendak bebasnya, manusia tidak selalu memilih yang benar. Demikian pula, karena kesadaran tentang dosanya, manusia tidak selalu memilih yang baik. Itulah sebabnya, ide besarnya tentang kebaikan Allah tersebut pada akhirnya mensyaratkan hadirnya penderitaan. Karena Allah adalah kasih, maka Ia mengizinkan penderitaan agar membuat makhluk ciptaan pada akhirnya menjadi lebih baik. ${ }^{50}$ Allah menginginkan manusia mendapatkan kebahagiaan sejati, bukan seperti apa yang dipikirkan oleh manusia. Manusia berpikir bahwa ia mengetahui dengan jelas apa yang bisa membuatnya bahagia tetapi Allah sebenarnya di dalam kasih-Nya memiliki rencana

\footnotetext{
${ }^{48}$ McInnis, Shadows and Chivalry: C. S. Lewis and George MacDonald on Suffering, Evil and Goodness, 55.

${ }^{49}$ Lewis, The Problem of Pain, 37-38.

${ }^{50}$ Ibid, 48.
} 
yang lebih indah. Manusia harus menyelami makna kebahagian yang sejati menurut paradigma Allah, termasuk melalui hadirnya penderitaan. ${ }^{51}$ Sebagai kesimpulan, bagi Lewis, karena kasih telah menjadi bagian dari natur Allah, maka Ia mengizinkan penderitaan itu dialami oleh manusia agar manusia mengalami kebaikan-Nya. Bagi Lewis, kebaikan-Nya mensyaratkan hadirnya penderitaan.

\section{Kehendak Bebas Mensyaratkan Konteks}

\section{Natural Kehidupan Manusia dengan}

Hukum-Hukum Alam yang Tetap dan

\section{Beraturan}

Lewis memahami konsep kehendak bebasnya dalam konteks libertarian. ${ }^{52}$ Ia memandang kehendak bebas manusia sebagai kemampuan untuk merespons kepada Allah, dalam rangka untuk menjadi lebih baik atau lebih buruk. ${ }^{53}$ Kebebasan yang Allah anugerahkan kepada manusia adalah kebebasan yang sejati sebagaimana pernyataannya: "the freedom of a creature must mean freedom to choose; and choice

\footnotetext{
51 Ibid.

${ }^{52}$ Kebebasan libertarian adalah kemampuan manusia untuk memilih melakukan sesutu yang berbeda dengan yang telah ia pilih. Penjelasan diri Lewis sebagai libertarian, dinyatakannya dalam Lewis, The Problem of Pain, 24-25.

53 Will Vaus, Mere Theology: A Guide to the Thought of C. S. Lewis (Downer Grove: InterVarsity, 2004), 49.

${ }^{54}$ Lewis, The Problem of Pain, 29.

${ }^{55}$ Vaus, Mere Theology: A Guide to the Thought of C. S. Lewis, 81.

${ }^{56}$ Ibid, 81-82. Gerard Reed dalam Gerard Reed, $C$.

S. Lewis and the Bright Shadow of Holiness, ed. Efie
}

implies the existence of things to choose between." 54 Kehendak bebas tersebut adalah kebebasan dari paksaan, baik internal maupun eksternal, tetapi bukan berarti bebas dari bujukan atau pengaruh, baik eksternal maupun internal, di dalam setiap keputusan yang merupakan tanggung jawab manusia. ${ }^{55}$ Kehendak bebas ini yang kemudian memungkinkan hadirnya kejahatan sebab Allah yang Mahakuasa dan Mahabaik dengan rela membatasi diri-Nya atau tidak campur tangan secara penuh pada diri manusia sehingga manusia mampu menikmati kebebasannya ${ }^{56}$ Di sini muncul pertanyaan, apakah ia menolak kedaulatan Allah sebagaimana yang tercatat dalam Alkitab? Mengenai hal ini, Will Vaus menjelaskan bahwa Lewis nampak tidak tertarik mengungkapkan konsepnya kedaulatan Allah dalam relasi dengan kehendak bebas dalam hubungan sebab akibat (sebagaimana dikerjakan oleh kompatibilisme), namun bukan berarti ia menolak kedaulatan Allah. ${ }^{57}$ Vaus mengatakan:

Shofia Sompie (Batam: Gospel, 2003), 67., menegaskan bahwa konsep: "isu kehendak bebas ini cukup memberinya [Lewis] alasan untuk menetapkan pijakan kakinya, dan dengan jelas dia berpijak pada penganut paham kehendak bebas. Dia tidak bisa memahami kalau Allah yang penuh kasih itu ingin 'robot' dan bukan anak-anak, dan dia yakin tidak bisa membentuk suatu rumus etika yang menghapus tanggung jawab manusia dari rumusannya.

57 Lihat pembahasan Vaus tentang penerimaan Lewis pada kedaulatan Allah dalam Vaus, Mere Theology: A Guide to the Thought of C. S. Lewis, 4961. 
He is the C. S. Lewis who is not, in the end, interested in reconciling human free will and God's sovereignty along logical-causal lines. He is the C. S. Lewis who is sure in his own case that his decision for Christ was not all that important. What is important is that he was "decided upon." God decision made all the difference in $C$. S. Lewis's life, as it has in many other lives before and since. ${ }^{58}$

Dengan kata lain, Lewis konsisten dengan pandangan libertariannya dan mengakui kedaulatan Allah namun ia tidak berusaha untuk mendamaikan atau menyatukan keduanya dalam satu konsep yang utuh dan konsisten. Lewis tetap pada asumsi awalnya bahwa manusia mampu datang kepada Kristus untuk keselamatan.

Bagi Lewis, masalah kejahatan memiliki peran penting bagi teisme sebab selain berfungsi sebagai argumen bagi eksistensi Allah, masalah kejahatan juga mampu menjadi petunjuk bagi realitas natur ciptaan. Pada waktu Ia menciptakan manusia dengan kebebasan yang sejati, hal tersebut mensyaratkan tersedianya suatu konteks natural kehidupan manusia. ${ }^{59}$ Di sini, Lewis melihat suatu relasi antara konteks natural kehidupan manusia tersebut dengan kesadaran diri tentang kehadiran Allah dan sesama manusia di luar dirinya, ${ }^{60}$ yang berdasar

\footnotetext{
58 Ibid, 61.

${ }^{59}$ Lewis, The Problem of Pain, 30. Lihat McInnis, Shadows and Chivalry: C. S. Lewis and George MacDonald on Suffering, Evil and Goodness, 57-59.
}

pada komitmennya kepada hukum alam yang telah Allah tetapkan.

Lebih lanjut, Lewis mengatakan bahwa kebebasan yang sejati tersebut menuntut suatu konteks natural kehidupan manusia yang harus memenuhi dua syarat yakni: secara relatif bersifat independen dan tidak bisa ditawar. ${ }^{61}$ Konteks natural kehidupan manusia yang relatif bersifat independen dan yang tidak bisa ditawar tersebut akan memungkinkan ciptaan untuk memilih dan pada akhirnya memberi peluang bagi hadirnya kebaikan, sekaligus penderitaan. Selain membutuhkan konteks natural kehidupan manusia, kebebasan yang sejati juga menuntut konteks natural kehidupan manusia tersebut bersifat tetap dan memiliki tatanan dan bukan sebaliknya, dengan tujuan agar manusia dapat menggunakan kehendak bebasnya. ${ }^{62}$ Akan tetapi, konteks natural kehidupan manusia yang bersifat tetap dan memiliki tatanan tersebut dapat membawa dampak sebaliknya apabila manusia mengeksploitasinya untuk melukai sesamanya (sebagai bentuk penyalahgunakan kehendak bebas yang Allah berikan). ${ }^{63}$ Bagi Lewis, suatu konteks natural kehidupan manusia yang stabil (dengan hukum alam) tersebut sangat penting bagi manusia karena

\footnotetext{
${ }^{60}$ McInnis, Shadows and Chivalry: C. S. Lewis and George MacDonald on Suffering, Evil and Goodness, 29.

${ }^{61}$ Ibid.

${ }^{62}$ Ibid, 31-32.

${ }^{63}$ Ibid, 33.
} 
mandatangkan kebaikan dan kebenaran. Manusia hidup berdasarkan atas tatatan natural yang alami, stabil dan beraturan. ${ }^{64}$ Prediktabilitas yang diberikan oleh keseragaman hukum alam, memungkinkan manusia bertumbuh dalam pemahaman moral, untuk itu, segala tindakan jahat haruslah berbuahkan kejahatan dan segala tindakan kebaikan haruslah berbuahkan kebaikan. Agar manusia dapat hidup dengan damai sejahtera serta produktif di dunia, manusia membutuhkan suatu konteks natural kehidupan manusia yang diatur oleh suatu hukum yang tetap dan beraturan. Konteks tersebut pada akhirnya membawa manusia kepada pengenalan akan kejahatan, sebab Allah tidak mungkin mencabut hukum gravitasi yang telah Ia tetapkan guna menyelamatkan seseorang yang jatuh dari atas jurang ataupun menghentikan pergerakan matahari demi menghindari wabah kekeringan di suatu tempat terpencil. Konteks natural kehidupan manusia yang tetap dan beraturan tersebut harus berlaku tanpa mengurangi sedikitpun eksistensi Allah sebagai yang Mahakuasa dan Mahabaik.

\section{Teodise Kebaikan yang Lebih Besar}

Lewis mengatakan bahwa penderitaan pada akhirnya menghancurkan tiga ilusi manusia yang menunjuk kepada kesom-

${ }^{64}$ Art Lindsey, "The Problem of Evil: C. S. Lewis Speaks to Life's Most Difficult Questions," https://www.cslewisinstitute.org/webfm_send/636. bongan manusia. Ilusi yang pertama adalah bahwa manusia ada dalam kondisi baikbaik saja. Ilusi yang kedua, bahwa manusia telah memiliki semuanya dan itu cukup. Ilusi yang ketiga adalah ilusi tentang keilahian manusia. Kehancuran ketiga ilusi tersebut pada akhirnya menjadikan manusia, mau tidak mau, kembali kepada Allah, mengembalikan mereka kepada sukacita dan menyerahkan kehendak mereka kepada-Nya. ${ }^{65}$ Dengan kata lain, untuk mewujudkan suatu kebahagiaan yang sejati, manusia harus sungguh-sungguh menundukan diri kepada Allah dalam ketaatan. ${ }^{66}$ Ketika manusia sepenuhnya menyerahkan diri dan tunduk kepada Allah, maka penderitaan akan berfungsi dalam mengembangkan kebajikan pada diri manusia.

Penderitaan juga akan mendatangkan kebaikan, baik bagi mereka yang menderita maupun mereka yang menyaksikannya. Ia mengatakan: "What is good in any painful experience is, for the sufferer, his submission to the will of God, and, for the spectators, the compassion aroused and the acts of mercy to which it leads." ${ }^{67}$ Maksudnya di sini adalah bahwa setiap pengalaman penderitaan tersebut akan memberikan insentif atau dorongan kepada mereka yang menderita untuk menundukkan diri pada

\footnotetext{
${ }^{65}$ Lewis, The Problem of Pain, 95-102.

${ }^{66}$ Ibid, 90, 100.

${ }^{67}$ Ibid, 110.
} 
Allah sedangkan bagi mereka yang menyaksikan merupakan kesempatan untuk menunjukkan kepedulian dan belas kasihan. ${ }^{68}$ Dalam sebuah suratnya ia juga mengatakan bahwa penderitaan kadang merupakan pembelajaran: "Every disability conceals a vocation, if only we can find it, which will 'turn the necessity to glorious gain." 69 Lewis juga mengaitkan keberadaan penderitaan dengan pembentukan jiwa manusia (soul-making) di mana pembentukan jiwa tersebut dimungkinkan oleh lingkungan atau materi dengan hukum-hukum alam yang stabil, sebagaimana dengan ucapan terkenalnya: "God whispers to us in our pleasures, speaks in our consciences, but shouts in our pains: it is His megaphone to rouse a deaf world."70 Baginya, dunia dengan segala penderitaan yang dikandungnya adalah suatu dunia pembentuk jiwa. ${ }^{71}$

\section{Perbandingan Konsep Teodise John}

\section{Calvin Dan C. S. Lewis}

Berdasarkan penguraian kedua konsep teodise di atas, berikut penulis akan

\footnotetext{
${ }^{68}$ Thomas Talbott, "C. S. Lewis and the Problem of Evil," Christian Scholar's Review 17, no. 1 (1987): 48.

${ }^{69}$ Walter Hooper, ed., The Collected Letters of C. S. Lewis (San Francisco: HarperCollins, 2007), 3:472.

${ }^{70}$ Lewis, The Problem of Pain, 93.

${ }^{71}$ Ibid, 108.

${ }^{72}$ Calvinisme berdasarkan pada pengajaran Agustinus, Luther dan tentunya Calvin, yang disebut dengan Reformed sejak dipopulerkan selama reformasi Protestan pada 1500-an. Secara spesifik didefinisikan dengan Lima Pokok Pikiran TULIP dalam
}

memberikan perbandingan singkat keduanya.

\section{Perbedaan}

Dalam konteks modern, perbedaan keduanya mewakili kubu Calvinisme dan kubu teisme klasik, ${ }^{72}$ meliputi konsepkonsep tentang: kejahatan, kedaulatan Allah, kehendak bebas dan kejatuhan, efek dosa atas manusia, serta penyataan kehendak-Nya. Premis utama Calvin adalah kedaulatan mutlak Allah atas seluruh ciptaanNya, dan bahwa atribut-atribut-Nya yang lain juga diletakkan pada kedaulatan-Nya tersebut, sedangkan premis utama Lewis ada pada kebaikan yang melekat pada diri Allah, bahwa semua kebaikan berasal dariNya, dan manusia dapat mengetahui kebaikan tersebut melalui alam ciptaan-Nya dan hukum alam, sehingga tidak terjadi konflik riil antara kebaikan dan kedaulatan-Nya. Dari sudut pandang Calvin, posisi Lewis adalah suatu kesalahan fatal karena telah menjadikan Allah tunduk pada sesuatu (kebaikan) yang berada di luar diri-Nya, se-

hubungannya dengan soteriologi, yang diformulasikan oleh Synod of Dort untuk menyanggah pengajaran Arminius. Sedangkan teisme klasik menekankan bahwa Allah adalah cukup (simple) di dalam esensi-Nya, sementara alam ciptaan-Nya bersifat kompleks. Teisme klasik menggunakan esensialisme ilahi (Divine Essentialism) untuk mendeterminasi di mana atribut-atribut-Nya tersebut bersifat penting atau layak bagi esensi-Nya. Teisme klasik ini berdasarkan pada Summa Theologica Aquinas. 
dangkan dari perspektif Lewis, Calvin telah menjadikan kedaulatan Allah sebagai konsep yang berkontradiksi secara logis dengan kebaikan Allah.

Calvin melihat kejahatan adalah kurangnya kebenaran dan sebuah permusuhan dengan Allah. Kejahatan bersumber dari kejatuhan manusia di mana dosa asal itu bermula. Sedangkan Lewis melihat kejahatan sebagai suatu korupsi dari kebaikan, sebab pada dasarnya tidak ada kejahatan yang bersifat murni. Calvin, dengan penekanannya pada kedaulatan Allah, memandang Dia sebagai penyebab segala sesuatu, Pencipta yang berdaulat, yang menjadikan alam semesta yang bersifat independen namun sepenuhnya bergantung pada pemeliharaanNya. Karakter providensia Allah tersebut bersifat partikular, meliputi peristiwa-peristiwa yang spesifik, terus-menerus dan aktif. Sedangkan Lewis, memandang Allah sebagai Pengarah atas segala sesuatu, yang mengendalikan semua peristiwa sementara memungkinkan manusia sebagai makhluk spiritual menyempurnakan kehendak bebas mereka. Calvin sangat menekankan ketidakberdayaan manusia secara spiritual karena semua manusia telah terkorupsi oleh dosa Adam. Sedangkan Lewis, dengan komitmennya kepada teologi natural, menolak

73 Layantara, "Determinisme, Masalah Kejahatan dan Penyebab Sekunder Menurut John Calvin.” kerusakan total manusia yang menjadi penekanan Calvin.

\section{Persamaan}

Disamping perbedaan di antara keduanya, ada beberapa persamaan yang membawa kedua konsep tersebut ke dalam kategori teodise kebaikan yang lebih besar. Keduanya sama-sama mengakui kemahakuasaan Allah sebagai premis awal, dan kejatuhan manusia ke dalam dosa sebagai sumber kejahatan. Pertanyaan penting yang harus dijawab kemudian adalah: apakah keduanya mampu membuktikan bahwa teodise mereka bukan fatalis? Pembahasan fatalisme menjadi tidak terlalu relevan pada Lewis sebab komitmennya pada kehendak bebas libertarian jelas menunjukkan bahwa ia bukan seorang fatalis, namun bagaimana dengan Calvin mengingat komitmennya terhadap determinisme ilahi?

Harus diakui, bahwa tuduhan fatalisme nampak layak disematkan pada doktrin providensia Allah Calvin yang menempatkan kedaulatan Allah sebagai sentral dari rumusan teologinya. ${ }^{73}$ Namun demikian, Calvin sendiri menolak fatalisme panteistik bahwa segala sesuatu sudah diatur oleh nasib dan takdir yang tak bepribadi. Ia melihat fatalisme lebih didasarkan pada penalaran labirin yang berkontradiksi, sedangkan predestinasi berdasarkan pada pemahaman 
Alkitab. ${ }^{74}$ Meskipun Calvin sangat menekankan kedaulatan Allah di dalam providensia-Nya namun pandangan Calvin bukan fatalisme teologis karena ia menekankan pentingnya tanggung jawab manusia dan pilihan manusia. Layantara menjelaskan: "Ajaran Calvin juga tidak pernah mengajarkan bahwa usaha manusia akan siasia dan lebih baik berdiam diri saja karena semua sudah ditentukan. Justru Calvin menekankan dalam pengajarannya bahwa umat Kristen harus melakukan sesuatu, seperti berdoa dan memberitakan Injil." 75 Pandangan Calvin tentang providensia Allah yang berjalan sesuai dengan kehendak bebas manusia ini dapat juga disebut sebagai kompatibilisme yakni determinisme ilahi sejalan dengan kehendak bebas manusia dan keduanya tidak bertentangan. ${ }^{76}$

\section{Relevansi Bagi Sikap Fatalisme di Dalam}

\section{Menghadapi Covid-19 di Indonesia}

Dalam kaitan dengan konteks kekristenan di Indonesia, khususnya dalam sikap menghadapi bencana COVID-19, penulis melihat studi ini menjadi sangat relevan.

\footnotetext{
74 Calvin, Calvin's Calvinism: A Treatise on the Eternal Predestination of God, 261-262.; Calvin, Institutes of the Christian Religion, I.xvi.8.

75 Layantara, "Determinisme, Masalah Kejahatan dan Penyebab Sekunder Menurut John Calvin."

76 Ammiël Meuleman and Willem van Vlastuin, "Calvin and Swaab: A Comparison with Respect to Free Will," In die Skriflig/In Luce Verbi 48, no. 1 (December 19, 2014): 4-5, accessed September 13, 2021, https://indieskriflig.org.za/index.php/skriflig/ article/view/1763/3944.
}

Relevansi tersebut meliputi beberapa aspek, pertama, kita tidak dapat dengan pasti mengetahui apa alasan di balik Tuhan mengizinkan suatu bencana seperti COVID-19 ini. Kondisi sosial dan dan alam Indonesia itu sendiri sangat potensial untuk menghadirkan bencana. ${ }^{77}$ Kondisi alam menyebabkan penderitaan yang disebabkan oleh kejahatan natural (seperti wabah penyakit, banjir, gempa bumi, gunung meletus, tsunami, tanah longsor, dan lain-lain) seperti akrab dengan masyarakat Indonesia. Orang Indonesia seringkali mengkaitkan bencana tersebut dengan Tuhan dibalik bencana. ${ }^{78}$ Kekristenan melihat bahwa ada Allah yang berdaulat atas segala sesuatu termasuk bencana dan segala sesuatu yang terjadi berada di dalam rencana Allah untuk menghasilkan kebaikan yang lebih besar. Tentu saja ini benar dan sesuai dengan teodise Calvin dan Lewis. Namun yang menjadi masalah adalah ketika orang Kristen dengan cepat dan pasti mampu memberikan alasan mengapa Allah mengizinkan kejahatan atau bencana alam ini terjadi. Alasan yang sering diberikan adalah bencana adalah hukuman Tuhan

\footnotetext{
${ }^{77}$ Hasrul Hadi, Sri Agustina, and Armin Subhani, "Penguatan Kesiapsiagaan Stakeholder Dalam Pengurangan Risiko Bencana Alam Gempabumi," Geodika: Jurnal Kajian Ilmu dan Pendidikan Geografi 3, no. 1 (July 1, 2019): 30-40, accessed September 13, 2021, http://e-journal.hamzanwadi. ac.id/index.php/gdk/article/view/1476.

78 Sabir, "Gambaran Umum Persepsi Masyarakat Terhadap Bencana Di Indonesia.”
} 
terhadap orang berdosa sehingga respons manusia yang tepat adalah bertobat, berdoa, mendekat kembali kepada Tuhan. Masalah dengan penjelasan ini adalah skop penjelasan yang terlalu sempit. Penjelasan ini tidak dapat menjelaskan fakta bahwa ada banyak orang Kristen yang baik bahkan pengerja gereja yang melayani Tuhan dengan baik menjadi korban bencana termasuk korban COVID-19 ini. Lagipula, di dalam Alkitab bencana dan penderitaan tidak selalu merupakan hukuman Tuhan seperti dalam peristiwa Ayub (Ayb. 1-2) dan orang yang lahir buta (Yoh. 9:1-3). Alasan lain yang sering diajukan adalah bencana alam dan COVID-19 ini adalah ujian dari Tuhan agar orang-orang Kristen lebih percaya dan bersandar pada Tuhan. Namun penjelasan ini juga bermasalah yakni tidak dapat menjelaskan penderitaan anak-anak yang terkena bencana dan COVID-19 serta binatang yang menderita karena bencana. Lebih jauh Alkitab juga menjelaskan bahwa kejahatan natural dapat juga merupakan hukuman Allah, disiplin dari Allah, dan untuk menunjukkan kemuliaan Allah. Di sini konsep Calvin tentang kehendak Allah yang tersembunyi perlu kita perhatikan dengan

\footnotetext{
79 Nur Hidayah, "Dari Jabariyah, Ke Qadariyah, Hingga Islam Progresif: Respons Muslim Atas Wabah Corona Di Indonesia," SALAM: Jurnal Sosial dan Budaya Syar-i 7, no. 5 (April 17, 2020): 423-438, accessed September 13, 2021, http:// journal.uinjkt.ac.id/index.php/salam/article/view/15 365.; Nurwina, "Pentingnya Moderasi Beragama Di
}

seksama. Ada alasan-alasan Tuhan mengizinkan kejahatan yang tidak selalu dapat kita ketahui dengan pasti dan benar karena kebesaran Allah dan keterbatasan kita manusia memahaminya. Sikap yang dengan pasti mengetahui alasan Allah mengizinkan kejahatan dan bencana atau kepastian bahwa tidak ada alasan bagi Allah mengizinkan kejahatan seperti yang dilakukan oleh kalangan ateis adalah mengabaikan ketersembunyian kehendak Allah.

Kedua, teodise Kristen menolak sikap fatalisme. Di dalam menghadapi bencana alam termasuk pandemi COVID-19 ini sikap fatalisme seringkali muncul baik di kalangan Muslim maupun Kristen. ${ }^{79}$ Sikap fatalisme membuat manusia Indonesia melepaskan tanggung jawabnya untuk bertindak mencegah, menanggulangi, dan mengentaskan bencana dan penderitaan dan menyerahkannya sepenuhnya kepada Tuhan. Padahal ada banyak bencana justru disebabkan oleh ulah manusia yang tidak bersahabat dengan alam. ${ }^{80}$ Teodise Kristen seperti yang diperlihatkan oleh Calvin dan Lewis menolak fatalisme teologis. Bagi mereka kebebasan manusia penting di dalam menghadapi penderitaan karena

Tengah COVID-19," in Bersama Melawan COVID19, ed. Islamul Haq (Parepare: Nusantara Press, 2020), 256.; Widyasto S. Raharjo, "Fatalisme Dalam Masyarakat Jawa" (Universitas Kristen Duta Wacana, 1994), 5-6.

80 Sabir, "Gambaran Umum Persepsi Masyarakat Terhadap Bencana Di Indonesia.” 
Allah menuntut pertanggung jawaban manusia atas apa yang mereka pilih untuk lakukan. Allah juga menggenapkan ketetapan-Nya di dalam sejarah dengan menggunakan keputusan-keputusan manusia yang bebas sehingga sejarah dimana manusia berbuat dan bertindak menjadi sesuatu yang penting bagi Allah. Apa yang manusia pilih, misalnya memilih untuk percaya Yesus Kristus sebagai Tuhan, merupakan sebuah tindakan yang memiliki dampak di dalam kekekalan dan di dalam sejarah hidup manusia. Di dalam kondisi pandemi COVID19 ini gereja dipanggil untuk memilih bertindak dengan "bersatu secara proaktif mengerjakan pelayanan kasih kepada sesama yang membutuhkan sebagai bentuk kemuridan yang menaati Tuhan Yesus Kristus yang telah lebih dulu mendemonstrasikan kasih Allah kepada dunia ini."

Ketiga, teodise Kristen menerima kemandirian relatif tatanan natural atau proses-proses alam yang natural suatu konsep yang ditekankan oleh Lewis dengan baik. Independensi proses-proses natural di dalam alam berarti bahwa Allah yang menopang dan menata sejarah sesuai dengan rencana-Nya tidak setiap saat melakukan mujizat mengintervensi proses-proses natural tersebut. Pengakuan akan kemandirian relatif proses-proses tersebut membuat kita

${ }^{81}$ David Alinurdin, "COVID-19 Dan Tumit Achilles Iman Kristen," Veritas: Jurnal Teologi dan Pelayanan 19, no. 1 (June 8, 2020): 1-9, accessed manusia dapat menggunakan sains dan penalaran untuk melakukan penyelidikan guna memahami, memprediksi, dan menanggulangi bencana berdasar hasil-hasil penyelidikan terhadap bencana-bencana tersebut termasuk pandemi COVID-19 ini. Sains dan penalaran bukan sesuatu yang bertentangan dengan kepercayaan orang Kristen kepada kedaulatan Allah. Sikap yang mengabaikan protokol kesehatan COVID-19 karena alasan bahwa kita harus lebih takut Tuhan dan Tuhan menjaga kita adalah mengabaikan pemahaman teologi bahwa Allah bekerja melalui hukum-hukum alam juga. Sikap seperti ini juga sama dengan mencobai Tuhan Allah dengan melakukan sesuatu yang kita tahu melalui proses dan hukum alam akan membawa dampak buruk dan bencana tapi membenarkannya dengan alasan pemeliharaan Allah. Sikap ini adalah sesuatu yang ditentang oleh Tuhan Yesus (Mat. 4:5-7).

\section{KESIMPULAN}

Penelitian ini memperlihatkan bahwa teodise John Calvin maupun C. S Lewis tidak jatuh ke dalam fatalisme teologis. Kedua-duanya sama-sama menekankan kehendak bebas dan tanggung jawab manusia di dalam melakukan pilihan dan tindakan. Hanya saja Calvin lebih menekankan kebebasan yang bersifat kompatibilistik sedang-

September 13, 2021, https://ojs.seabs.ac.id/index. php/Veritas/article/view/373. 
kan Lewis lebih menekankan kebebasan libertarian. Calvin juga menekankan ketersembunyian kehendak Allah sehingga kita manusia tidak tahu dengan pasti kebaikan apa yang muncul dari bencana dan kejahatan. Sehingga sikap yang tepat adalah tunduk kepada otoritas firman Tuhan yang memerintahkan kita untuk bertindak dengan berbuat baik kepada sesama yang menderita dan sakit.

\section{UCAPAN TERIMA KASIH}

Penelitian ini merupakan penelitian kolaboratif bersama. Sebab itu penulis mengucapkan terima kasih kepada Esther Gunawan yang sudah melakukan penelitian ini bersama dengan penulis sejak dari awal penelitian sampai kepada selesainya paper ini khususnya di dalam deskripsi dan perbandingan teodise John Calvin dan C. S. Lewis.

\section{DAFTAR PUSTAKA}

Alinurdin, David. "COVID-19 Dan Tumit Achilles Iman Kristen." Veritas: Jurnal Teologi dan Pelayanan 19, no. 1 (June 8, 2020): 1-9. Accessed September 13, 2021. https://ojs.seabs .ac.id/index.php/Veritas/article/view/3 73.

Calvin, John. Calvin's Calvinism: A Treatise on the Eternal Predestination of God. Translated by Henry Cole. Grand Rapids: Reformed Free, 1994. Psalms Vol. I. Translated by James Anderson. Edinburgh: Calvin Translation Society, 1945.
Institutes of the Christian Religion. Translated by John T. McNeill. Philadelphia: Westminster, 1960.

- Sermons from Job. Translated by Leroy Nixon. Port St. Lucie: Solid Ground Christian Books, 2011.

- Sermons on the Beatitudes. Edinburgh: Banner of Truth, 2006.

Campbell, Ronnie P. Worldviews and the Problem of Evil. Bellingham: Lexham Press, 2019.

Christian, Grace P., ed. Mere Christianity. Bandung: Pioner Jaya, 2006.

Ebenezer, Matthew. "Calvin and Human Response to Suffering in the Psalm" (n.d.).

Gunawan, Esther. "Meneropong Makna Penderitaan Manusia Menurut Konsep Teodise C.S. Lewis." Veritas: Jurnal Teologi dan Pelayanan 16, no. 1 (June 1, 2017): 17-32. Accessed September 13, 2021. https://ojs.seabs.ac.id/index. $\mathrm{php} /$ Veritas/article/view/8.

Hadi, Hasrul, Sri Agustina, and Armin Subhani. "Penguatan Kesiapsiagaan Stakeholder Dalam Pengurangan Risiko Bencana Alam Gempabumi." Geodika: Jurnal Kajian Ilmu dan Pendidikan Geografi 3, no. 1 (July 1, 2019): 30-40. Accessed September 13, 2021. http://e-journal. hamzanwadi.ac.id/index.php/gdk/artic le/view/1476.

Helm, Paul. John Calvin's Ideas. Oxford: Oxford University Press, 2006.

- The Providence of God. Grand Rapids: InterVarsity Press, 1994.

Hidayah, Nur. "Dari Jabariyah, Ke Qadariyah, Hingga Islam Progresif: Respons Muslim Atas Wabah Corona Di Indonesia." SALAM: Jurnal Sosial dan Budaya Syar-i 7, no. 5 (April 17, 2020): 423-438. Accessed September 13, 2021. http://journal.uinjkt.ac.id/ index.php/salam/article/view/15365. 
Hoefer, Carl. "Causal Determinism." Stanford Encyclopedia of Philosophy, 2016. https://plato.stanford.edu/ entries/determinism-causal/\#Int.

Hooper, Walter, ed. The Collected Letters of C. S. Lewis. San Francisco: HarperCollins, 2007.

Van Horn, Luke. "On Incorporating Middle Knowledge into Calvinism: A Theological/Metaphysical Muddle?" JETS 55, no. 4 (2012): 807-834.

Kilby, Clyde S. The Christian World of $C$. S. Lewis. Grand Rapids: Eerdmans, 1964.

Kinlaw, C. J. "Determinism and the Hiddenness of God in Calvin's Theology." Religious Studies 24, no. 4 (1988): 497-509. Accessed September 13, 2021. https://www.cambridge. org/core/journals/religiousstudies/article/abs/determinism-andthe-hiddenness-of-god-in-calvinstheology/55183C355FAB9E17D78D B43AE69D4C18.

Layantara, Jessica Novia. "Determinisme, Masalah Kejahatan dan Penyebab Sekunder Menurut John Calvin." Jurnal Amanat Agung 11, no. 2 (December 1, 2015): 297-332. Accessed September 10, 2021. https://ojs.sttaa.ac.id/index.php/JAA/a rticle/view/181.

. "Kritik Terhadap Teologi Proses Dan Pembelaan Terhadap Pandangan 'Greater Good' Dalam Menanggapi Masalah Kejahatan." Veritas: Jurnal Teologi dan Pelayanan 16, no. 2 (December 1, 2017): 155-168. Accessed September 10, 2021. https:// ojs.seabs.ac.id/index.php/Veritas/artic le/view/16.

Lewis, C. S. "Miracles." In The Complete C. S. Lewis Signature Classics, edited by Joseph Rutt. San Francisco: Harper, 2002.
- "The Abolition of Man." In The Complete C. S. Lewis Signature Classics, edited by Joseph Rutt. San Francisco: Harper, 2002.

. The Problem of Pain. New York: Macmillan, 1968.

Lindsey, Art. "The Problem of Evil: C. S. Lewis Speaks to Life's Most Difficult Questions." https://www. cslewisinstitute.org/webfm_send/636.

McCauley, Matthew Duvalier. "The Problem of Theological Fatalism." Logos 11, 2014.

McInnis, Jeff. Shadows and Chivalry: C. S. Lewis and George MacDonald on Suffering, Evil and Goodness. Milton Keynes: Paternoster, 2007.

Meister, Chad V. Evil: A Guide for the Perplexed. 2nd ed. New York: Bloomsbury, 2018.

Meuleman, Ammiël, and Willem van Vlastuin. "Calvin and Swaab: A Comparison with Respect to Free Will." In die Skriflig/In Luce Verbi 48, no. 1 (December 19, 2014). Accessed September 13, 2021. https:// indieskriflig.org.za/index.php/skriflig/ article/view/1763/3944.

Miller, Timothy E. "Reformed Theodicy: Calvin's View of the Problem of Evil." Puritan Reformed Journal 10, no. 1 (2018).

Nurwina. "Pentingnya Moderasi Beragama Di Tengah COVID-19." In Bersama Melawan COVID-19, edited by Islamul Haq. Parepare: Nusantara Press, 2020.

Partee, Charles. Calvin and Classical Philosophy. Westminster: John Knox, 1977.

Raharjo, Widyasto S. "Fatalisme Dalam Masyarakat Jawa." Universitas Kristen Duta Wacana, 1994. 
Reed, Gerard. C. S. Lewis and the Bright Shadow of Holiness. Edited by Efie Shofia Sompie. Batam: Gospel, 2003.

Rhoda, Alan R. "Gratuitous Evil and Divine Providence." Religious Studies 46, no. 3 (September 2010): 281-302. Accessed September 10, 2021. https:// www.cambridge.org/core/journals/reli gious-studies/article/abs/gratuitousevil-and-divineprovidence/5C4B9995EA2D6533870 3174DCA6F61AE.

Ruhana, Akmal Salim, and Haris Burhani. Pengetahuan, Sikap Dan Tindakan Umat Beragama Menghadapi Covid19, 2020. https://simlitbangdiklat. kemenag.go.id/simlitbang/spdata/uplo ad/dokumen-penelitian/1592454380 Laporan_UmatVSCovid_.pdf.

Sabir, Ahmad. "Gambaran Umum Persepsi Masyarakat Terhadap Bencana Di Indonesia." Jurnal Ilmu Ekonomi dan Sosial 5, no. 3 (2016): 304-326.

Sayer, George. Jack: C. S. Lewis and His Times. New York: Harper \& Row, 1988.
Steffaniak, Jordan. "Bound by the Word of God: John Calvin's Religious Epistemology." Puritan Reformed Journal 10, no. 2 (2018).

Talbott, Thomas. "C. S. Lewis and the Problem of Evil." Christian Scholar's Review 17, no. 1 (1987).

Vaus, Will. Mere Theology: A Guide to the Thought of C. S. Lewis. Downer Grove: InterVarsity, 2004.

Velarde, Robert. Conversations with C. S. Lewis: Imaginative Discussions about Life, Christianity and God. Downers Grove: InterVarsity, 2008.

Vorster, Nico. "The Augustinian Type of Theodicy: Is It Outdated?" Journal of Reformed Theology 5, no. 1 (January 1, 2011): 26-48. Accessed September 10, 2021. https://brill.com/view/ journals/jrt/5/1/article-p26_4.xml.

Concerning the Eternal Predestination of God. London: James Clarke, 1997. 